\section{AJHSE Vol: 1 (1): 01-10, 2020}

Article Ref. No.: AJHSE-0101-03

Accepted Date: Jan. 22, 2020

(C) 2020. CC License 4.0

www.ajhse.org
African Journal of Health, Safety and Environment

An official publication of the

Applied Environmental Bioscience and Public Health Research Group

University of Benin, Benin City, Nigeria

Open Access | Bi-annual | Peer-reviewed | International

ISSN (Online): 2695-1819 | ISSN (Print): 2695-2386

\title{
A QUANTITATIVE TEST OF THE PREDICTIVE VALIDITY OF HEINRICH'S ACCIDENT PYRAMID
}

\section{*nwuka C.}

*Department of Occupational Safety and Health, Columbia Southern University (CSU), Orange Beach, Alabama, USA.

*Phone: +2347043319172 *Email: eaglesgambit@gmail.com

\begin{abstract}
$\mathrm{H}$ erbert W. Heinrich, a pioneer researcher in the field of occupational safety, published a book on occupational accidents in 1931. In the publication, Heinrich presented an Accident Pyramid, which affirmed that one workplace fatality would occur after 300 no-injury accidents have been recorded in a workplace. Heinrich's Accident Pyramid has since been adopted as a standard for predicting the likelihood that fatalities will occur. Moreover, Heinrich's claim on occupational accidents was adopted as a standard because of his reputation as a pioneer of occupational safety research. This study seeks to test the statistical hypothesis put forward by Heinrich in reference to General Aviation (GA) accidents and does so with a random subsample of the National Transportation Safety Board (NTSB) data. Retrospective data published for public use by NTSB was collected from 2004 to 2013 for 15,119 GA accidents (with a mean fatal accident count of $\approx 282$ ). The pyramid was initially recommended for use in predicting all forms of accidents, including GA accidents. Notwithstanding, the analysis of an independent variable $\mathrm{x}$, the number of total accidents, and a dependent variable $\mathrm{y}$, the number of fatalities, produced a p-value of approximately 0.821 , which indicates no correlation between the variables. There was no statistically significant relationship found between the total number of accidents and fatal accidents, as asserted by Heinrich. This study, therefore, demonstrates that Heinrich's Accident Pyramid is statistically invalid. Consequently, this means that a fatality may still occur even if the total number of accidents is reduced.
\end{abstract}

Keywords: accident prevention, accident pyramid, accident prediction, Heinrich, workplace safety

LICENSE: This article by African Journal of Health, Safety and Environment (AJHSE) is licensed and published under the Creative Commons Attribution License 4.0 International License, which permits unrestricted use, distribution, and reproduction in any medium, provided this article is duly cited.

COPYRIGHT: The Author(s) completely retain the copyright of this published article.

OPEN ACCESS: The Author(s) approves that this article remains permanently online in the open access (OA) mode. 


\section{INTRODUCTION}

Heinrich is a pioneer in the field of accident prevention. Four editions of "Industrial Accident Prevention: A Scientific Approach," representing his research work on accident causation and prevention, were published within approximately 30 years. Furthermore, Heinrich is widely praised for drawing attention to the need for employers and governments to focus on workplace accident prevention as a means of eliminating the injuries suffered by workers in various occupational work environments. In addition, Heinrich has more influence in the field of occupational safety and health, concerning accident causation and prevention, than any other occupational safety practitioner in recent history (Manuele, 2011). Heinrich's work on accident prevention has influenced the work of others in the field of occupational safety like Frank E. Bird, author of The Accident Triangle. In 1970, Frank E. Bird, an employee of the Insurance Company of North America, pursued and disseminated Heinrich's theories on accident causation and prevention (Manuele, 2011). Bird asserted that based on the analyses of data from 1.7 million accidents reported by 297 cooperating companies, the ratio between fatal accidents, incidents and minor incidents is relatively constant, over-time, in occupational work environments. Bird's conclusions on accident causation and prevention strongly collaborates Heinrich's theories on this topic (Manuele, 2011). Heinrich's theories on accident causation and prevention are widely accepted by many people in the field of occupational safety as a standard. His study's research problem was focused on showing a connection between significant accidents and minor injuries in work environments. The study's research question was, "Is there a relationship between significant injuries and minor accidents?"

Nevertheless, Stefansson, a renowned human social behavior expert, cautioned experts in the field of science and technology not to willingly accept written or spoken theories that do not have adequate compelling scientific evidence as fact (Cambridge University Press, 2011). Stefansson further states that theories presented as facts in all fields of academic research and study, except mathematics, must be questioned. He recommends that knowledge and theories must only be accepted as facts if they can be proven and cannot be logically contradicted (Cambridge University Press, 2011). Following Stefansson's admonitions, some researchers and scholars in the field of occupational safety and health have questioned the predictive validity of Heinrich's Accident Pyramid. For instance, Heinrich's Accident Pyramid suggests that all hazard types follow a linear pattern towards the causation of an incident. However, Bellamy (2008) argued that an analysis of the occupational accidents recorded in the Netherlands shows that within a specific hazard type, many hazard types are not linear, thus, proving Heinrich's theories to be invalid.

Furthermore, in an article written by Marshall, Hirmas, and Singer (2018), which was published in the Safety Science journal, the authors stated that an analysis of occupational accidents across all the industries in Chile over 28months shows that the ratio of fatal, serious and minor workplace accidents do not follow the ratio of accidents described in Heinrich's Accident Pyramid. Therefore, the team concluded that Heinrich's theory on the relationship between major and minor accidents is statistically invalid for all the industrial sectors in Chile. Similarly, in the Risk Analysis journal, Yorio and Moore (2017) published an article titled "Examining factors that influence the existence of Heinrich's safety triangle using site-Specific H\&S data from more than 25,000 establishments." In this article, the authors studied the incident data from mines in the United States to confirm the predictive validity of Heinrichs's Accident Pyramid by checking if a certain number of incidents at a mine will produce a corresponding number of 
fatalities at the same mine. The results of their study did not match the figures described by Heinrich in his pyramid of accidents.

For instance, the authors concluded that there is no significant probability that a certain total number of minor accidents will result in a corresponding number of fatal events in the mines as described in Heinrich's Accident Pyramid. Therefore, one may hypothesize that the occurrence of a certain total number of negligible or non-fatal accidents will not result in a corresponding number of fatal accidents in an industrial work environment. As such, the purpose of this study was to test quantitatively, the predictive validity of Heinrich's Accident Pyramid by further investigating the relationship between the number of total accidents and the number of fatal accidents recorded in the aviation industry, in order to affirm the future acceptance of Heinrich's Accident Pyramid as a fact or myth.

According to Heinrich's Accident Pyramid, $0.3 \%$ of all accidents recorded in an industrial work environment will produce major injuries like fatalities, $09.0 \%$ of these accidents will produce minor workplace injuries, while approximately $90.7 \%$ of them will produce no injuries. These numbers hypothetically suggest a ratio of 1:30:300 and assert that in a unique set of approximately 331 identical workplace accidents, 300 will result in no injuries, approximately 30 will cause only minor injuries, and only one will lead to a severe occupational workplace injury like a fatality (Saloniemi et al., 1998) Heinrich represented his statistical hypothesis on the likelihood of the occurrence of a major accident in a workplace using a pyramid.

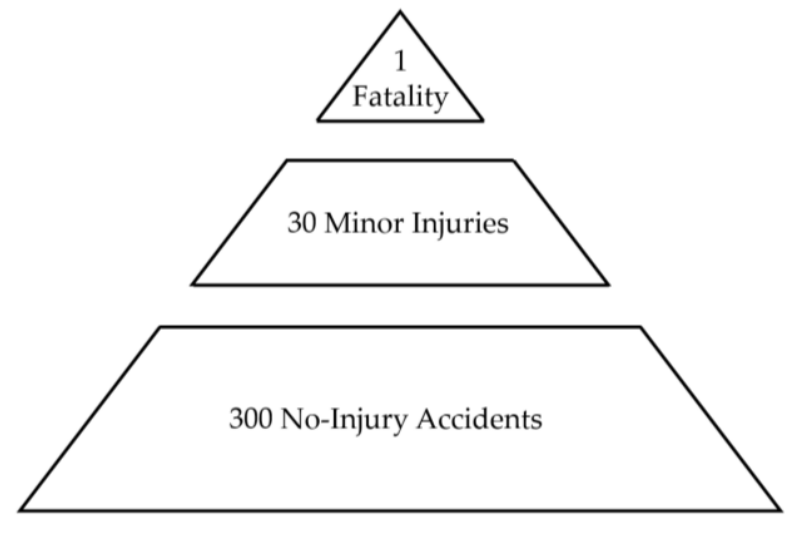

Figure 1. An Illustrative Description of Heinrich's Accident Pyramid.

Source: Saloniemi et al. (1998).

\section{RESEARCH OBJECTIVES}

Research objectives are the goals of a research project (Cooper and Schindler, 2011). The goal of this research project is not to callously undermine Heinrich's reputation but to scrutinize the statistical hypothesis he made in the description of his Accident Pyramid using appropriate statistical methods of data analysis. Furthermore, the research objective for this research study aims to:

RO1: Determine if the total number of accidents is relative to the number of fatal accidents.

The total number of accidents was the independent variable and the number of fatal accidents was the dependent variable. 


\section{RESEARCH QUESTIONS AND HYPOTHESIS}

The research questions with corresponding null and alternative hypotheses for this research study are;

$\mathbf{R Q}_{1}$ : Is there a relationship between the total number of accidents and the number of fatal accidents?

H01: There is a statistically significant relationship between the total number of accidents and the number of fatal accidents.

HA: There is no statistically significant relationship between the total number of accidents and the number of fatal accidents.

\section{MATERIAL AND METHODS}

Retrospective data published for public access and use by the United States National Transportation Safety Board (U.S. National Transportation Safety Board, 2013) was collected from 2004 to 2013 for 15,119 general aviation accidents (with a mean fatal accident count of $\approx 282$ ). The details of the data source elements collected for analysis include the total number of aviation accidents recorded each year from 2004 to 2013, the total number of fatal aviation accidents recorded each year from 2004 to 2013, as well as the total number of General Aviation (GA) flight hours from 2004 to 2013. Furthermore, the total number of flight hours logged from 2004 to 2013 is approximately 201.57 million hours, and 2,817 fatal accidents occurred between 2004 and 2013 (U.S. National Transportation Safety Board, 2013). A regression analysis was carried out using the total number of accidents each year from 2004 to 2013 and the number of fatal accidents that occurred in this period. This analysis was done to test the predictive validity of Heinrich's Accident Pyramid. Some aviation safety experts have suggested that Heinrich's Accident Pyramid can be applied in the prediction of general aviation accidents caused by airplane stalls and spins. Besides, the Federal Aviation Authority (FAA) had approved the use of this claim as part of training programs organized for small airplane pilots (Stowell, 2007).

The research methodology was primarily divided into two types, the quantitative methodology and qualitative methodology. Nevertheless, the research methodology for this research study was quantitative (Creswell and Creswell, 2018). The application of a quantitative methodology involves the testing of scientific assumptions using numbers. Moreover, with quantitative methodology, the emphasis is placed on collecting numerical data, summarizing these data, and drawing inferences from them. Additionally, quantitative methodology allows the research team to remain objective, and conclusions are made referencing the statistical data. On the other hand, qualitative methodology is based on words, feelings, emotions, sounds and other non-numerical and unquantifiable elements. Therefore, subjectivism is the ontology adopted in a qualitative methodology (Creswell and Creswell, 2018).

Nevertheless, a quantitative methodology was chosen over the qualitative methodology for this research study because the data available for the research were tangible and quantifiable. Similarly, actual data would be collected and analyzed to adequately determine if there was a relationship between the total number of accidents and fatal accidents. Moreover, a qualitative methodology would not introduce this element in the research process. Therefore, the quantitative methodology was adopted as the suitable means of achieving the purpose of this research study.

Based on the quantitative research methodology adopted to answer research questions, a suitable research method to pursue will include a combination of descriptive statistics, correlation, and casual-comparative methods. 
These were carried out following standard statistical methods of data analysis. Consider the following research questions and hypotheses for the research paper:

$\mathbf{R Q}_{1}$ : Is this focused on determining if there is a relationship between the total number of accidents and the number of fatal accidents?

H01: There is a statistically significant relationship between the total number of accidents and the number of fatal accidents.

HA1: There is no statistically significant relationship between the total number of accidents and the number of fatal accidents.

\section{RESEARCH DESIGN AND SAMPLING DESIGN}

Furthermore, as the aim of this research was not to manipulate the data but to analyze it as it is, the quantitative research design adopted for this study was non-experimental. The descriptive non-experimental research can accommodate descriptive statistics, correlational or causal-comparative research methods; hence, the dataset obtained for this research study was statistically analyzed using descriptive regression analysis.

As sampling design, a selection of individual data from the dataset under review was analyzed, and conclusions were subsequently drawn for the entire dataset analyzed. Also, the type of sampling design used for this research study was random subsamples. Using random subsamples is a cost-effective way of achieving accurate results (Cooper and Schindler, 2011).

\section{RESULTS}

Table 1: A Table of data for all GA Accidents recorded in the United States between 2004 and $2013(n=15119)$.

\begin{tabular}{ccc}
\hline & General Aviation Accidents, 2004-2013 \\
\hline Calendar Year & Total Aviation Accidents & Fatal Aviation Accidents \\
\hline 2004 & 1619 & 314 \\
2005 & 1671 & 321 \\
2006 & 1523 & 308 \\
2007 & 1654 & 288 \\
2008 & 1568 & 277 \\
2009 & 1480 & 275 \\
2010 & 1440 & 271 \\
2011 & 1470 & 269 \\
2012 & 1470 & 272 \\
2013 & 1224 & 222 \\
\hline
\end{tabular}

Retrospective data published for public access and use by the United States National Transportation Safety Board Source: U.S. National Transportation Safety Board (2013). 
Table 2: Frequency Distribution Table of GA Accidents data recorded in the United States between 2004 and 2013

\begin{tabular}{ll}
\hline Annual Estimates of Total Accidents and Fatal Accidents between 2004 - 2013 & Frequency \\
\hline 1400 & 1 \\
1600 & 6 \\
1700 & 3 \\
\hline
\end{tabular}

Table 3: Descriptive Statistics Table of GA Accidents data recorded in the United States between 2004 and $2013(n=15119)$.

\begin{tabular}{ll}
\hline \multicolumn{1}{c}{ Annual Estimates of Total Accidents and Fatal Accidents } \\
\hline Mean & 1500 \\
Standard Error & 44.10939683 \\
Median & 1480 \\
Mode & 1470 \\
Standard Deviation & 132.3281905 \\
Sample Variance & 17510.75 \\
Kurtosis & 1.767721693 \\
Skewness & -0.854735025 \\
Range & 447 \\
Minimum & 1224 \\
Maximum & 1671 \\
Sum & 13500 \\
Count & 9 \\
\hline
\end{tabular}

Source: U.S. National Transportation Safety Board (2013).

The descriptive statistics for the dataset that was analyzed strongly suggest that the data are normally distributed, though they appear negatively skewed. Similarly, to test the assumption of a normal distribution, skewness and kurtosis should be within the range \pm 2 . Moreover, both the kurtosis, 1.7677 and the skewness, -0.8547 are relatively close to zero and fall within these expected ranges, suggesting that the data is normally distributed. Therefore, the assumption of normality is met, and a parametric test would be acceptable to test the collected data.

\section{NULL HYPOTHESIS TESTING USING SIMPLE REGRESSION METHODOLOGY}

H01: There is a statistically significant relationship between the total number of accidents and the number of fatal accidents.

Table 4: Hypothesis Testing of the Null Hypothesis

\begin{tabular}{lcl}
\hline & Total Number of Accidents Each Year & Fatal Accidents \\
\hline Total Number of Incidents Each Year & 1 & 1 \\
Fatal Incidents & 0.889294284 & 1 \\
\hline
\end{tabular}


Table 5: Summary Output of the Regression Analysis of the Null Hypothesis

\begin{tabular}{ll}
\hline \multicolumn{2}{c}{ Regression Statistics } \\
\hline Multiple R & 0.889294284 \\
R Square & 0.79 \\
Adjusted R Square & 0.764699864 \\
Standard Error & 13.83401817 \\
Observations & 10 \\
\hline
\end{tabular}

Table 6: ANOVA Analysis of the Null Hypothesis

\begin{tabular}{llllll}
\hline & df & SS & MS & F & Significance F \\
\hline Regression & 1 & 5789.05953 & 5789.05953 & 30.24902159 & 0.000573805 \\
Residual & 8 & 1531.04047 & 191.3800588 & & \\
Total & 9 & 7320.1 & & & \\
\hline
\end{tabular}

Table 7: Coefficients and Intercept of the independent variable $x$ and the dependent variable $y$

\begin{tabular}{lllllllll}
\hline & & Standard & & & Lower & Upper & Lower & Upper \\
& Coefficients & Error & t Stat & P-value & $\mathbf{9 5 \%}$ & $\mathbf{9 5 \%}$ & $\mathbf{9 5 . 0 \%}$ & $\mathbf{9 5 . 0 \%}$ \\
\hline Intercept & -12.6 & 53.68 & -0.23 & 0.82097012 & -136 & 111.2 & -136 & 111.2 \\
X Variable 1 & 0.195 & 0.035 & 5.5 & 0.0005738 & 0.113 & 0.276 & 0.113 & 0.276 \\
\hline
\end{tabular}

The intercept coefficient is approximately -12.6 while the slope, represented by the total number of incidents coefficient, is approximately 0.1946 , therefore the regression model is given as $\mathrm{y}=0.1946 x-12.6$

\section{INTERPRETATION OF ANALYSIS}

Using an alpha of 0.05 , the results of the analysis indicate a $p$-value approximately 0.821 , which is considerably larger than the alpha of 0.05. Therefore, the null hypothesis, which states that there is a statistically significant relationship between the total number of accidents and the number of fatal accidents, is rejected, and the alternative hypothesis is accepted.

Furthermore, an increase in the $\mathrm{x}$ variable using the regression model $\mathrm{y}=0.1946 x-12.6$ will not result in the occurrence of a significant accident in an industrial work environment, as suggested by Heinrich in his Accident Pyramid. For instance, substituting x with 300 in the derived regression model will not result in one significant injury y.

$y=0.1946(300)-12.6=58.38-12.6=45.78$ 
Additionally, a visual analysis of the Bar Chart of data in Figure 2 showing the relationship between the total number of accidents and fatal aviation accident recorded between 2004 and 2013 does not indicate that there is a statistically significant relationship between the total number of accidents and the number of fatal accidents.

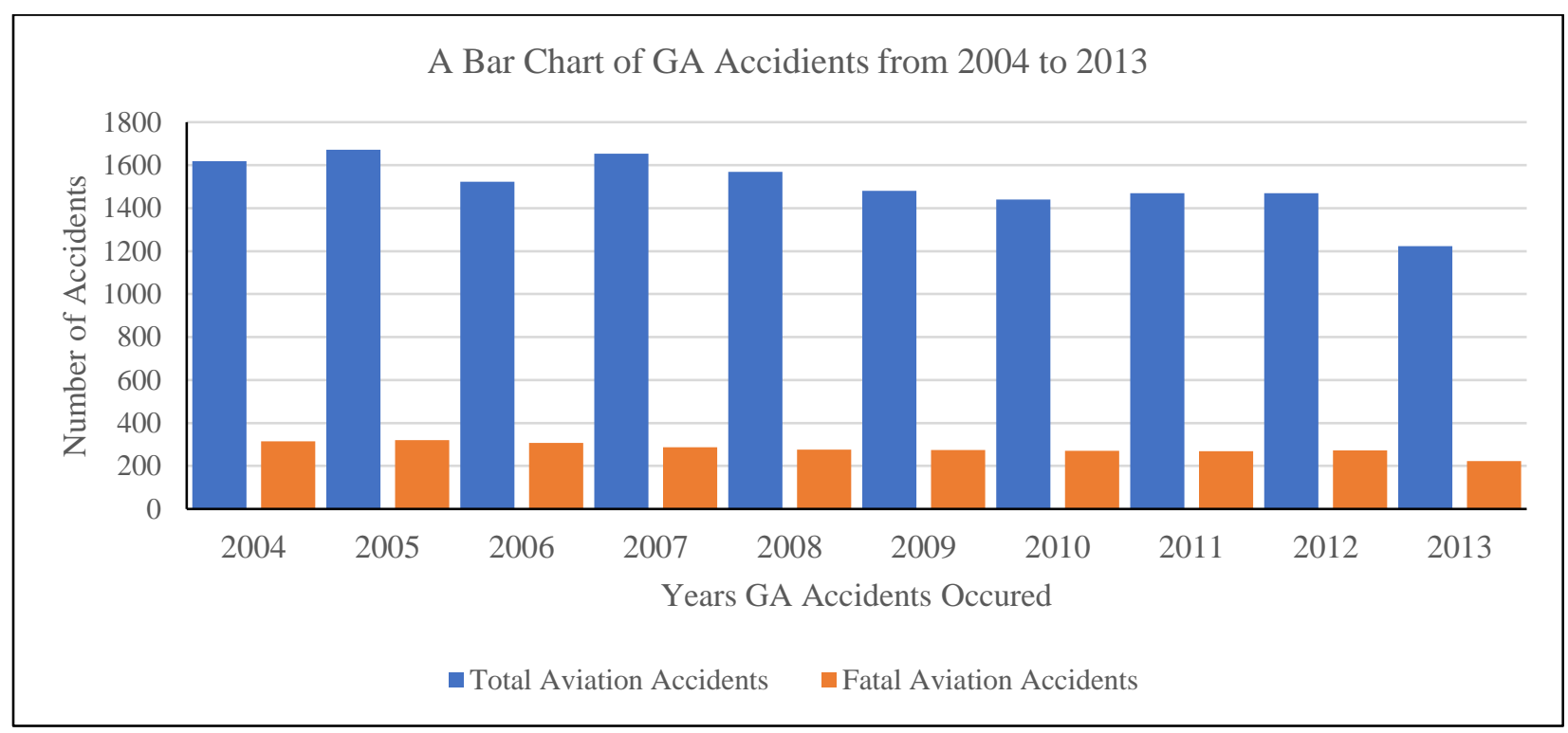

Figure 2: Bar Chart of GA Accidents from 2004 to 2013

Source: U.S. National Transportation Safety Board (2013).

\section{DISCUSSION}

An analysis of the data collected by the U.S. National Transportation Safety Board (U.S. National Transportation Safety Board, 2013) from 2004 to 2013 contributed to the achievement of the research objective for this research. Furthermore, the various hypotheses developed for this research study were tested to answer the research question. The data was critically analyzed, and an inference was made based on the evidence available from the analysis. For instance, for the research objective:

RO1: Determine if the total number of accidents is related to the number of fatal accidents.

The results of the statistical testing indicate that there is no statistically significant relationship between the total number of accidents and the number of fatal accidents. Though there is a relatively strong and positive correlation between the total number of accidents and fatal accidents, the analyzed data shows that a certain number of accidents will not yield a corresponding number of fatal accidents as suggested by Heinrich's Accident Pyramid. Consequently, this means that fatalities may still occur even if the total number of accidents is reduced. Therefore, this determination suggests that reducing the total number of accidents alone will not prevent fatalities.

Nevertheless, a Safety Management System (SMS) can be used to prevent fatalities and other accidents in occupational work environments. This model seeks to determine the accident causation factors in the workplace and follows a proactive and continuous improvement approach to accident prevention in industrial work environments. 
Moreover, this method is a more effective method of accident prevention compared to Heinrich's Accident Pyramid model.

\section{SAFETY MANAGEMENT SYSTEM (SMS) MODEL}

A typical Safety Management System (SMS) model uses a continuous improvement approach to solve recognized incident causation factors, thereby preventing accidents in an industrial work environment. Furthermore, this model is based on the Plan-Do-Check-Act (PDCA) methodology that aids the proactive identification, control, and mitigation of safety and health risks in occupational work environments.

In the Plan phase, the organization must develop a strategy for incident prevention. The Do phase of the SMS model involves the execution of the developed strategy for incident prevention. The Check phase is used to monitor and assess the effectiveness of the implemented incident prevention strategy, while the Act phase is used to study and improve the overall incident prevention strategy developed for the organization (Deming, 1986).

The successful execution of an SMS model can help prevent fatal accidents in an industrial work environment. For instance, in 2011, the Coca-Cola Company implemented an SMS model worldwide following BS OHSAS 18001 and ISO 45001, two internationally recognized SMS frameworks. Consequently, between 2011 and 2017, the company has not recorded any fatalities (The Coca-Cola Company, 2019). Similarly, Costain, a British construction company, implemented BS OHSAS 18001, a first-level SMS model. The company has not recorded any fatal accidents because they implemented this SMS model. Evidence has shown that implementing an SMS will result in almost $100 \%$ prevention of fatal accidents in an industrial work environment (The British Standards Institution, 2019).

Given that there is no statistically significant relationship between the total number of accidents and fatal accidents, as indicated by the evidence available from this study, the leadership teams in organizations must ensure that they do not depend on a near miss or non-fatal accident reduction alone for the prevention of fatalities in an industrial work environment. Organizations should adopt the SMS process to ensure workplace safety. An SMS model involves the continuous improvement of the various components of an organization's safety program following the PDCA principle. SMS helps safety professionals to identify the hazards that are inherent in an occupational work environment proactively, and subsequently use hazard control techniques to eliminate these hazards to promote the safety of personnel and the environment (Deming, 1986).

\section{CONCLUSION}

The analyzed quantitative data from the U.S. NTSB dataset made available for this research paper has shown that Heinrich's Accident Pyramid is not statistically valid. Furthermore, a regression analysis of GA accidents recorded between 2004 and 2013 indicates that there is no statistical correlation between the total number of accidents that occur in an industrial work environment to the number of fatal accidents that will occur in the same environment. Additionally, this means that a certain number of accidents will not result in a corresponding number of fatalities in the workplace. Therefore, leaders must not depend on accident reduction alone to keep employees, visitors and 
contractors safe. Instead, they must proactively identify and mitigate the hazards presented by the operations executed routinely in a workspace.

\section{REFERENCES}

Ale, J. Y., Andrew, R., Baksteen, H., Bellamy, J., Ben, J. M., Bloemhoff, M., Damen, M., Hale, I. A., Linda J., Mud, H., Papazoglou, A., and Whiston, M. L. (2008). The software tool Storybuilder and the analysis of the horrible stories of occupational accidents. Safety Science, 46(2): 186-97. doi: 10.1016/j.ssci.2007.06.002

Cambridge University Press. (2011). Standardized error and Japanese character: A note on political interpretation. World Politics, 2(3): 439-443. doi: https://doi.org/10.2307/2008914

Cooper, D. R., and Schindler, P. S. (2011). Business research methods (11th ed., pp. 15-27). New York, NY: McGrawHill/Irwin.

Creswell, J. W., and Creswell, J. D. (2018). Research design: Qualitative, quantitative, and mixed methods approaches (5th ed., pp. 20-23). Thousand Oaks, CA: Sage.

Deming, W. E. (1986). Out of the crisis. (1 $1^{\text {st }}$ ed., pp.34-49). Cambridge, MA: Center for Advanced Engineering Study, Massachusetts Institute of Technology.

Manuele, F. A. (2011). Reviewing Heinrich Dislodging Two Myths from the Practice of Safety. Professional Safety, 56(10): 52-61. Retrieved on $18^{\text {th }}$ October 2019 from https://www.worldcat.org/title/reviewingheinrich-dislodging-two-myths-from-the-practice-of-safety/oclc/757583805

Marshall, J., Pablo, J., Alejandro, H., and Marcos, S. (2018). Heinrich's pyramid and occupational safety: A statistical validation methodology. Safety Science 101(1): 180-89. doi: 10.1016/j.ssci.2017.09.005

Saloniemi, A., and Oksanen, H. E. (1998). Accidents and fatal accidents - some paradoxes. Safety Science. 29(1): 5966. doi: 10.1016/S0925-7535(98)00016-2

Stowell, R. (2007). The light airplane pilot's guide to stall/spin awareness: Featuring the PARE spin recovery checklist ( $1^{\text {st }}$ ed., pp. 57-60). Ventura, Calif.: Rich Stowell Consulting.

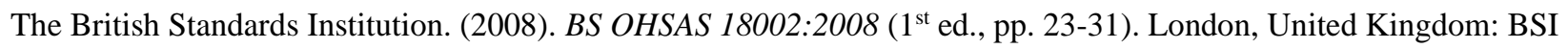
Standards.

The Coca-Cola Company. (2019). Safety ABC's always be careful ( $1^{\text {st }}$ ed., pp. 13-15). Atlanta, ATL: The Coca-Cola Company.

U.S. National Transportation Safety Board. (2013). General aviation 2013. NTSB json. 1(1): 1-2. Retrieved on $10^{\text {th }}$ February 2020 from https://catalog.data.gov/dataset/general-aviation-2013

Yorio, J., Patrick L., and Susan M. M. (2018). Examining factors that influence the existence of Heinrich's safety triangle using site-Specific H\&S data from more than 25,000 establishments. Risk Analysis, 38(4): 839-52. doi: 10.1111/risa.12869 